\title{
A novel direct coupling of simultaneous thermal analysis (STA) and Fourier transform-infrared (FT-IR) spectroscopy
}

\author{
A. Schindler $\cdot$ G. Neumann $\cdot$ A. Rager $\cdot$ \\ E. Füglein $\cdot$ J. Blumm $\cdot$ T. Denner
}

Received: 29 September 2012/ Accepted: 19 February 2013/Published online: 26 March 2013

(c) The Author(s) 2013. This article is published with open access at Springerlink.com

\begin{abstract}
Evolved gas analysis (EGA) from thermal analyzers such as thermogravimetry (TG) or simultaneous thermal analysis (STA) which refers to simultaneous TG-DSC is well established since it greatly enhances the value of TG or TG-DSC results. The sensitive and selective FT-IR technique is in particular useful for the analysis of organic molecules but also for infrared active permanent gases evolved during most decomposition processes. The coupling interface between thermal analyzers and FT-IR spectrometers usually consists of heated adapters and a flexible, heated transfer line. In this work, a novel direct coupling of an STA instrument and an FT-IR spectrometer without a transfer line is presented. A very small FT-IR spectrometer is directly mounted on top of the STA furnace leading to a compact and fully integrated STA-FT-IR coupling system. The possibilities and the value of simultaneous STA-FT-IR measurements are demonstrated for organic, biomass, and ceramic samples in the temperature range between room temperature and about $1,500{ }^{\circ} \mathrm{C}$. Various samples from the field of inorganics and organics-especially polymers-were furthermore measured showing the advantages of the direct STA-FT-IR coupling compared to state-of-the-art STA-FT-IR coupling using a heated transfer line: we found that the time delay caused by the volume of the transfer line itself is rather negligible whereas a significantly better correlation between gas detection and TG results was
\end{abstract}

\footnotetext{
A. Schindler $(\bowtie) \cdot$ G. Neumann $\cdot$ E. Füglein $\cdot$ J. Blumm

T. Denner

NETZSCH-Gerätebau GmbH, Wittelsbacherstraße 42,

95100 Selb, Germany

e-mail: alexander.schindler@netzsch.com

A. Rager

BRUKER Optik GmbH, Rudolf-Plank-Straße 27,

76275 Ettlingen, Germany
}

observed in case of some highly condensable decomposition gases. Aspects of quantification of evolved gases are furthermore discussed as well as the known nonlinearity of FT-IR detection at higher gas concentrations.

Keywords Evolved gas analysis (EGA) - STA . FT-IR · Coupling $\cdot$ Perseus $\cdot$ Pulse TA

\section{Introduction}

In general, evolved gas analysis (EGA) greatly enhances the value of thermogravimetry (TG) experiments since the identification of gases released from a sample allows for a better interpretation of mass loss steps and enables furthermore to draw conclusions about the chemical composition of a sample. Coupling of Fourier transform-infrared spectroscopy (FT-IR) to thermal analyzers such as thermogravimetry instruments was established as one possibility for evolved gas analysis [1]. The FT-IR technique which detects the infrared absorbance of molecules due to their vibrational modes is a sensitive and very selective method especially for organic molecules. It is therefore widely used for investigation of the decomposition of polymers [2] or biomass samples [3]. Upon heating, ceramic and inorganic samples release mostly gases like $\mathrm{H}_{2} \mathrm{O}, \mathrm{NH}_{3}$, $\mathrm{CO}_{2}$, or $\mathrm{SO}_{2}$ which can also be detected and distinguished via their characteristic infrared spectra. Ceramic fillers in composite samples do in turn influence the properties of polymers like their flame retardancy which can be studied by FT-IR coupled thermal analysis systems, too [4].

Simultaneous thermal analysis (STA) refers to the simultaneous measurement of TG and differential scanning calorimetry (DSC) on the same sample in the same instrument. The DSC signal shows caloric effects due to 
mass loss or mass gain of a sample but also due to structural phase transformations which are not associated with mass changes [5, 6]. Such efficient and highly flexible STA instruments offer furthermore a wide temperature range from about -150 to $2,400{ }^{\circ} \mathrm{C}$ and thus a broad application range. Another advantage compared to stand-alone TG instruments is the possibility of measuring samples with significantly larger volume and mass in an STA instrument. Sample sizes of several $\mathrm{cm}^{3}$ and sample masses of several grams are possible revealing a resolution of the smallest effects in the ppm range [7].

The coupling interface between TG or STA and FT-IR (or MS) instruments usually consists of a flexible heated transfer line as well as heated adapters where heating of the coupling interface is necessary in order to avoid condensation of evolved gases. Although integrated software solutions are available, the well-established transfer line coupling can be regarded as a connection of two physically separated instruments. It has furthermore two potential disadvantages: the transfer line causes a slight delay between the release and the detection of evolved gases and, moreover, condensation or interaction effects are possible.

In this work, a novel, direct coupling between STA and FT-IR is presented which stands out due to the absence of any transfer line. The FT-IR spectrometer is located directly on top of the STA furnace resulting in a very compact and fully integrated STA-FT-IR coupling system. Apart from the possibilities and the value of STA-FT-IR measurements, in general, the advantages of the direct coupling compared to transfer line coupling are demonstrated. Aspects of quantification of the evolved gases are furthermore discussed on the base of measurements on $\mathrm{CaCO}_{3}$ where the calibration of detected FT-IR signals for $\mathrm{CO}_{2}$ was also based on pulse thermal analysis (Pulse $\mathrm{TA}^{\circledR}$ ) [8]. Finally, the nonlinearity of FT-IR detection at higher gas concentrations is addressed and its relevance for typical applications is shown for $\mathrm{NaHCO}_{3}$.

\section{Experimental}

Figure 1 displays the direct STA-FT-IR coupling system called Perseus. The small type "alpha" FT-IR spectrometer from Bruker [9] with dimensions of only $31 \times 22 \times 14 \mathrm{~cm}(l \times w \times h)$ is mounted on top of the furnace of a NETZSCH STA 449 Jupiter $^{\circledR}$ so that the distance between the sample and the gas cell of the FT-IR spectrometer is only $25 \mathrm{~cm}$ and the footprint of the entire system is identical to the footprint of the STA unit $(52 \times 57 \mathrm{~cm})$. Condensation of evolved gases is minimized since the short connection tube between the furnace and the gas cell of the FT-IR spectrometer is heated, too (see Fig. 2, top). STA and FT-IR instruments can mechanically be coupled together or separated easily. The vertical and vacuum tight design of the entire system Perseus STA 449 is in particular advantageous for evolved gas analysis since the evolved gases follow the natural upward flow of hot gases and the vacuum tightness allows for defined inert gas atmospheres. For a comparison, most of the samples were measured also using the conventional transfer line coupling technique (see Fig. 2, bottom). The length of the flexible transfer line which has a Teflon tube in the center was $100 \mathrm{~cm}$ and the inner diameter of the Teflon tube was $0.2 \mathrm{~cm}$. The temperature of the transfer line was constantly at $250{ }^{\circ} \mathrm{C}$.

The relatively small FT-IR gas cell of the FT-IR spectrometer "alpha" with a volume of $5.8 \mathrm{~cm}^{3}$ and an optical path length of $7 \mathrm{~cm}$ was made from stainless steel and has single $\mathrm{ZnSe}$ windows at both ends which restrict the spectral range of operation between about 500 and $6,000 \mathrm{~cm}^{-1}$. Nickel-coated aluminum alloy will be investigated as cell material in the future in order to improve the chemical inertness and thermal conductivity. Heating of the gas cell is software controlled at a temperature of up to $200{ }^{\circ} \mathrm{C}$. The detector of the FT-IR spectrometer which is of

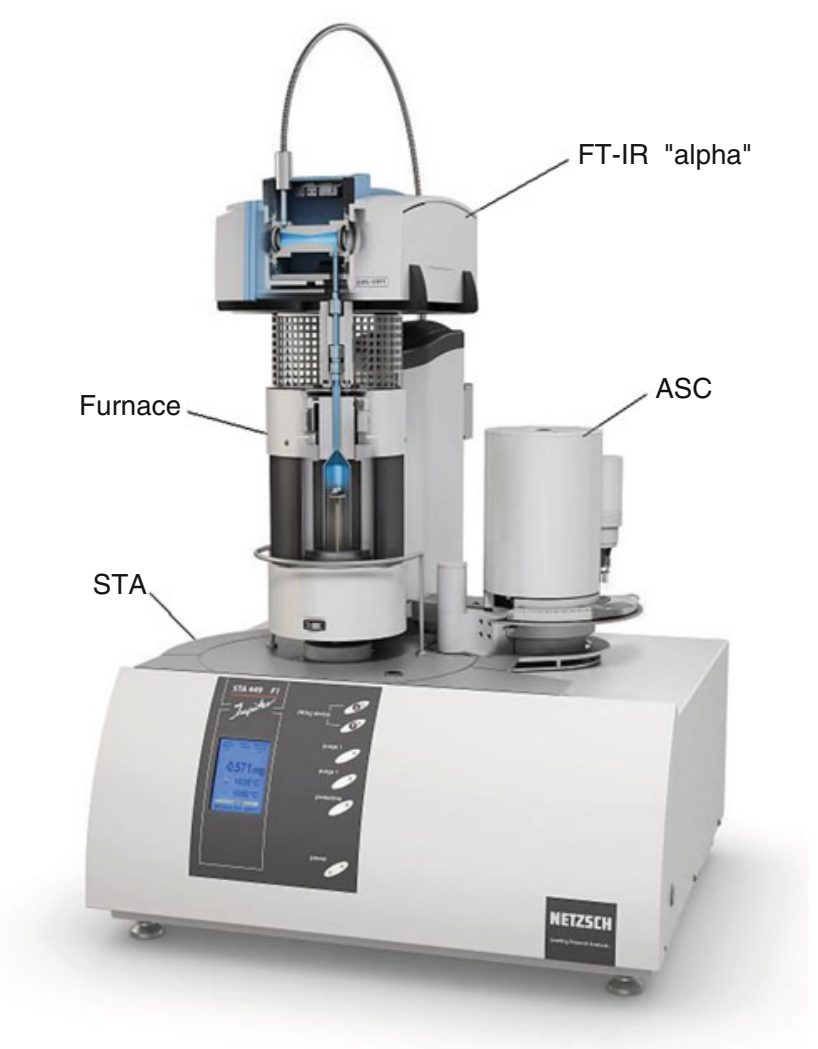

Fig. 1 NETZSCH Perseus STA 449: the Bruker type "alpha" FT-IR spectrometer coupled directly to an STA 449 Jupiter $^{\circledR}$ simultaneous thermal analyzer equipped with an optional automatic sample changer (ASC). The sample space of the furnace, the heated coupling interface as well as the gas cell of the FT-IR spectrometer are shown partially transparent in order to display the path of the evolved gases 

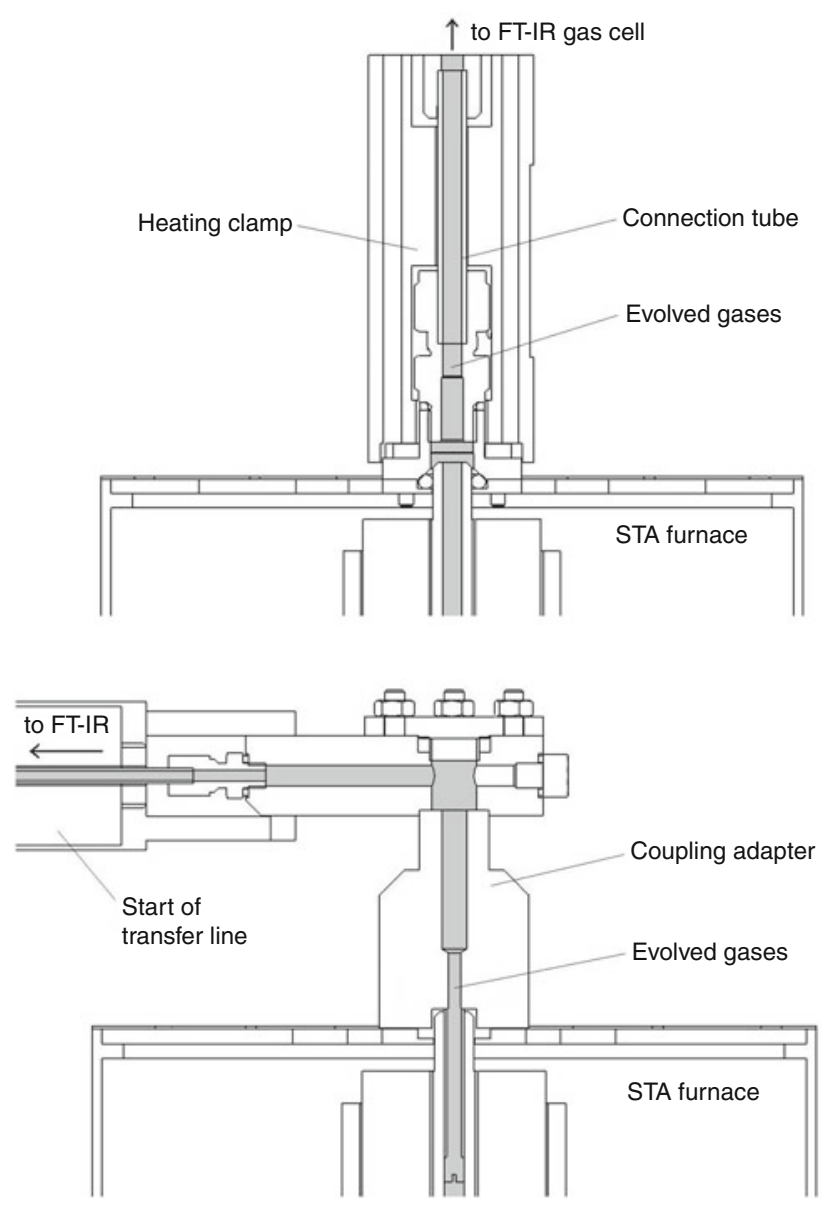

Fig. 2 Interface of direct FT-IR coupling NETZSCH Perseus STA 449 (top) compared to coupling with a (flexible) transfer line (bottom)

deuterated triglycine sulfate (DTGS) type works at spectrometer temperature and requires thus no liquid nitrogen like for example mercury cadmium telluride (MCT) detectors do.

The basic instrument NETZSCH STA 449 Jupiter $^{\circledR}$ enables to measure high resolution TG and DSC or DTA simultaneously in a wide temperature range of -150 and $2,400{ }^{\circ} \mathrm{C}$ depending on the furnace and sample carrier used [7]. In this work, TG-DSC and TG sample carriers with thermocouples type $\mathrm{S}$ and a PtRh furnace were applied. STA measurements were done mostly using PtRh or alumina crucibles with a volume of $85 \mu \mathrm{L}$, and nitrogen purge gas with a purity of about $99.999 \%$ and a flow rate of $70 \mathrm{~mL} \mathrm{~min}^{-1}$ (see also below). All STA results shown are baseline-corrected which means that empty-run signals were subtracted.

FT-IR acquisition was carried out at a resolution of $4 \mathrm{~cm}^{-1}$ and 16 scans were averaged for one FT-IR spectrum where one scan took about $1 \mathrm{~s}$. Just the sample $\mathrm{CaCO}_{3}$ was measured with a higher time resolution using only 4 scans per spectrum.

Quantification of evolved gases was also studied using pulse thermal analysis (NETZSCH PulseTA ${ }^{\circledR}$ ) [8]. This device enables-even online during a sample measurement- to inject defined volumes of calibration gas into a thermal analyzer leading to a calibration for this gas. Two different volumes ("loops") of nominally 0.25 and $1.00 \mathrm{~mL}$ were used and the calibration gas was a mixture of nominally $9.9 \% \mathrm{CO}_{2}$ in $90.1 \% \mathrm{~N}_{2}$.

\section{Results and discussion}

\section{Application examples}

In order to demonstrate STA-FT-IR capabilities at relatively low temperatures $\left(<250{ }^{\circ} \mathrm{C}\right)$, the bicyclic aromatic hydrocarbon naphthalene $\mathrm{C}_{10} \mathrm{H}_{8}$ was measured. Naphthalene belongs in general to the class of polycyclic aromatic hydrocarbons (PAHs) which are potent mutagens and carcinogens [10]. As an application of thermal analysis, the thermal desorption of PAH contamination from soil was investigated earlier [11]. In this work, naphthalene with an initial sample mass of $11.03 \mathrm{mg}$, aluminum crucibles with pierced lids, a heating rate of $10 \mathrm{~K} \mathrm{~min}^{-1}$ and dynamic nitrogen atmosphere (flow rate: $70 \mathrm{~mL} \mathrm{~min}^{-1}$ ) were used. The resulting mass changes, the heat flow rate (DSC) and the Gram-Schmidt signal which reflects the sum of the entire IR absorbance for all wavenumbers can be seen from Fig. 3. An endothermic DSC peak with an enthalpy of $138 \mathrm{~J} \mathrm{~g}^{-1}$ occurred which is due to melting of the sample. The extrapolated onset temperature of $81^{\circ} \mathrm{C}$ can be identified as the melting point. A mass loss step of $\sim 100 \%$ was detected between about 150 and $240{ }^{\circ} \mathrm{C}$ which reflects complete evaporation of the sample. This effect was accompanied by an endothermic DSC peak with an enthalpy of $287 \mathrm{~J} \mathrm{~g}^{-1}$ and an extrapolated onset temperature of $215{ }^{\circ} \mathrm{C}$. The latter reflects the boiling point of the sample. The Gram-Schmidt signal is very similar to the (inverted) DTG curve reflecting an excellent correlation between the mass loss and the evolved gases detected by the FT-IR spectrometer. This can be attributed to the relatively low gas volumes and the vertical design of the setup resulting in fast response times. Figure 4 displays the entire FT-IR data of the naphthalene sample which are temperature- and wavenumber-dependent together with the TG curve.

Again, a good correlation between the FT-IR absorbance and the mass loss can be seen from this 3D view. The wavenumber-dependent spectrum at maximum mass loss rate is characteristic for naphthalene (see Fig. 5).

The biomass straw was furthermore investigated using STA-FT-IR. Straw has in general several applications one of which is its use as a $\mathrm{CO}_{2}$ neutral source of energy. A powdered straw sample with an initial mass of $28.64 \mathrm{mg}$ was measured in a Pt crucible with pierced lid at a heating 
Fig. 3 Temperature-dependent mass change (TG), rate of mass change (DTG, dashed), heat flow rate (DSC), and GramSchmidt signal (GS) of a naphthalene sample

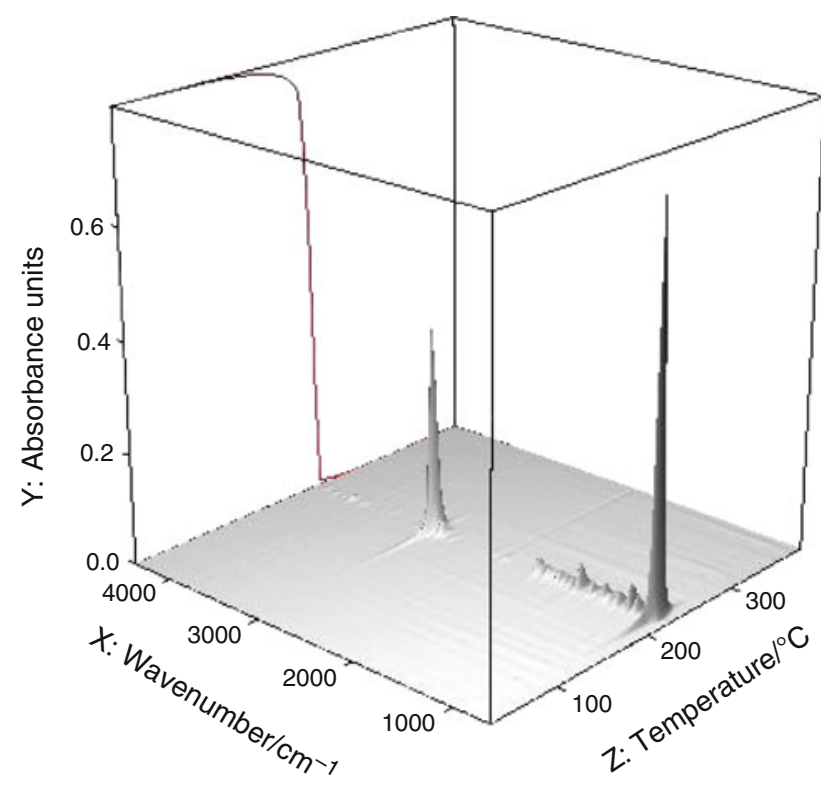

Fig. 4 Wavenumber-dependent FT-IR absorbance of the naphthalene sample as a function of temperature. The corresponding TG curve is shown in the left $Z Y$ plane

rate of $20 \mathrm{~K} \mathrm{~min}^{-1}$. The gas atmosphere was changed from pure nitrogen to air at $740{ }^{\circ} \mathrm{C}$ (the gas flow rate was $70 \mathrm{~mL} \mathrm{~min}{ }^{-1}$ ). Below $740{ }^{\circ} \mathrm{C}$, three mass loss steps of 4.9 , 33.8 , and $35.8 \%$ occurred which were accompanied by one endothermic and two overlapping exothermic effects with enthalpies of 125 and $-115 \mathrm{~J} \mathrm{~g}^{-1}$ (see Fig. 6). During these mass loss steps, the Gram-Schmidt signal showed maxima at 111,302 , and $360{ }^{\circ} \mathrm{C}$ which correlates again well with the DTG curve. Another mass loss step of $20.9 \%$ as well as an exothermic effect with an entire enthalpy of
$-7.79 \mathrm{~kJ} \mathrm{~g}^{-1}$ occurred after switching to air at $740{ }^{\circ} \mathrm{C}$. These observations are due to the burn-up of the so called pyrolytic soot while the residual mass of $4.6 \%$ reflects the ash content. The 3D view of the entire FT-IR data of the straw visible in Fig. 7 is particularly interesting below $740{ }^{\circ} \mathrm{C}$ where the pyrolysis of the sample occurred. The strong FT-IR absorbance at higher temperatures is due to the release of $\mathrm{CO}_{2}$ as a result of the burn-up.

By means of a comparison with library data, the characteristic FT-IR absorbance spectra can be identified as it is shown for one temperature in Fig. 8. At $302{ }^{\circ} \mathrm{C}$, the permanent gases $\mathrm{CO}_{2}$ and $\mathrm{CO}, \mathrm{H}_{2} \mathrm{O}$ as well as organic molecules such as formic acid $\mathrm{HCOOH}$ were detected. An integration of the FT-IR absorbance within characteristic wavenumber ranges reveals so called traces. The range between 2,200 and $2,450 \mathrm{~cm}^{-1}$ was integrated for $\mathrm{CO}_{2}$, between 1,950 and $2,150 \mathrm{~cm}^{-1}$ for $\mathrm{CO}$, between 1,300 and $1,600 \mathrm{~cm}^{-1}$ for $\mathrm{H}_{2} \mathrm{O}$, and between 1,000 and $1,150 \mathrm{~cm}^{-1}$ for $\mathrm{HCOOH}$. As it can be seen from Fig. 9, $\mathrm{H}_{2} \mathrm{O}$ is released during the first mass loss step (evaporation of moisture) and during the second and third mass loss step (pyrolysis), where also $\mathrm{CO}, \mathrm{CO}_{2}$, and $\mathrm{HCOOH}$ were evolved. $\mathrm{CH}_{4}$ occurred in a broad range with a maximum at $534^{\circ} \mathrm{C}$, and $\mathrm{CO}_{2}$ was detected again above $740{ }^{\circ} \mathrm{C}$ as a result of the burn-up in air atmosphere.

As a typical high temperature application example, a topaz powder sample of $57.72 \mathrm{mg}$ was measured in a dynamic nitrogen atmosphere (flow rate: $70 \mathrm{~mL} \mathrm{~min}^{-1}$ ) at a heating rate of $20 \mathrm{~K} \mathrm{~min}^{-1}$. Platinum crucibles with pierced lids were used for the measurement. The mineral topaz consists nominally of $\mathrm{Al}_{2} \mathrm{SiO}_{4}(\mathrm{~F}, \mathrm{OH})_{2}$ where the exact amounts of $\mathrm{F}$ and $\mathrm{OH}$ are, however, not known in case of the measured sample. Figure 10 depicts an 
Fig. 5 FT-IR spectrum of the naphthalene sample measured at $223{ }^{\circ} \mathrm{C}$ (top) together with the database spectrum of naphthalene (bottom). The spectra were rescaled and shifted for clarity

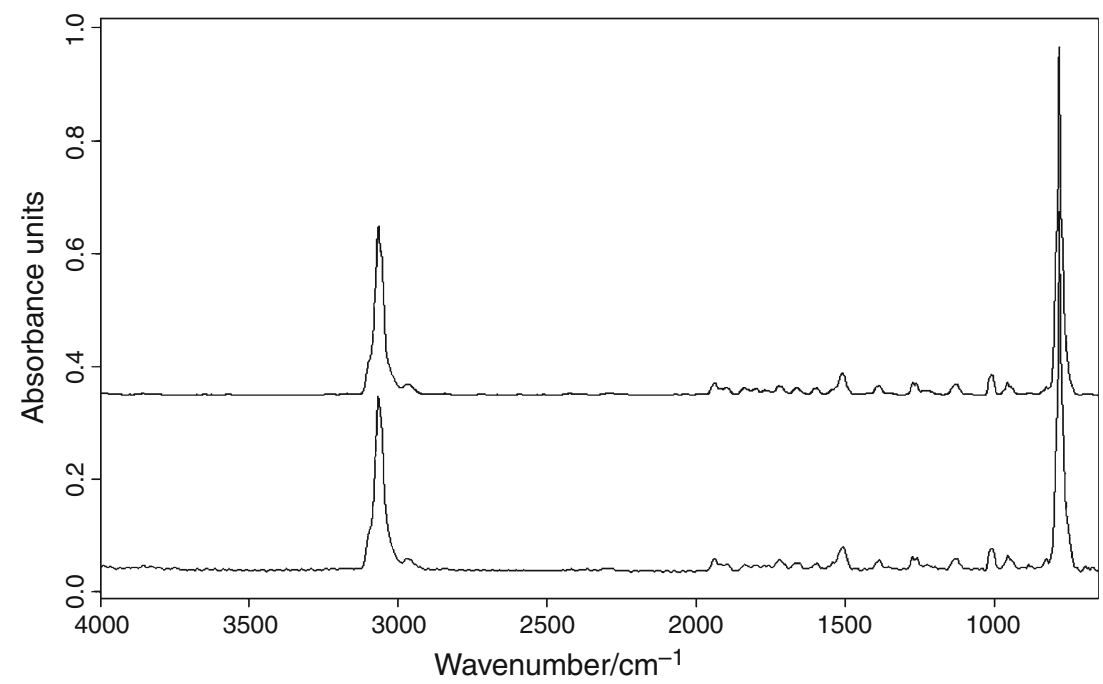

Fig. 6 Temperature-dependent mass change (TG), rate of mass change (DTG, dashed), heat flow rate (DSC), and GramSchmidt signal (GS) of a straw sample. The gas atmosphere was switched from nitrogen to air at $740{ }^{\circ} \mathrm{C}$

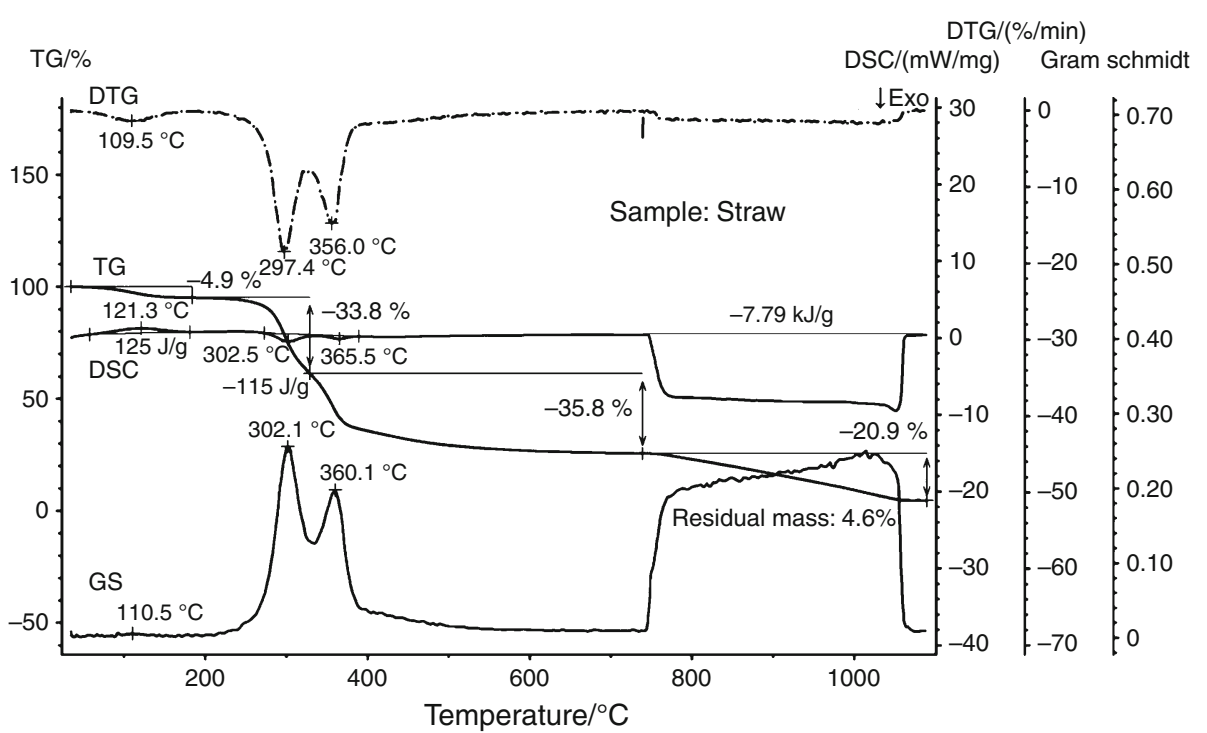

overview of the STA-FT-IR results above $800{ }^{\circ} \mathrm{C}$ (the sample did not show any effects below $800{ }^{\circ} \mathrm{C}$ ). Above about $1,100{ }^{\circ} \mathrm{C}$, three mass loss steps of $1.1,13.0$, and $6.7 \%$ were observed; maxima in the rate of mass change occurred at $1,196,1,317$, and $1,357^{\circ} \mathrm{C}$. The DSC signal exhibited three overlapping endothermic effects with an entire enthalpy of $523 \mathrm{~J} \mathrm{~g}^{-1}$. These endothermic effects with peak temperatures at $1,201,1,320$, and $1,357{ }^{\circ} \mathrm{C}$ are due to the mass loss steps. The Gram-Schmidt signal is again in reasonable correlation with the mass loss as well: a weak maximum occurred at $1,209^{\circ} \mathrm{C}$ and further peak temperatures are at 1,324 and $1,356{ }^{\circ} \mathrm{C}$.

Figure 11 shows the entire FT-IR data of the topaz sample together with the TG curve again in a $3 \mathrm{D}$ view. The database search illustrated in Fig. 12 revealed that the FTIR spectrum measured at $1,333{ }^{\circ} \mathrm{C}$ can be explained in terms of $\mathrm{HF}$ and $\mathrm{SiF}_{4}$ which have characteristic absorbance bands between about 3,700 and $4,200 \mathrm{~cm}^{-1}$ (HF) and an absorption peak at about $1,030 \mathrm{~cm}^{-1}\left(\mathrm{SiF}_{4}\right)$. The evolvement of these gases can be expected during the partial decomposition of topaz. After the release of $\mathrm{HF}$ and $\mathrm{SiF}_{4}$, the sample transformed most probably into different forms of mullite like $\left(2 \mathrm{Al}_{2} \mathrm{O}_{3}\right) \cdot \mathrm{SiO}_{2}$.

From the 3D cube shown in Fig. 11, it is already visible that the evolvement of $\mathrm{HF}$ and $\mathrm{SiF}_{4}$ occur at different temperatures. This becomes obvious from the traces for HF and $\mathrm{SiF}_{4}$ which were calculated integrating the FT-IR absorbance in the range of 4,000 and $4,200 \mathrm{~cm}^{-1}$ for $\mathrm{HF}$ and between 990 and $1,050 \mathrm{~cm}^{-1}$ for $\mathrm{SiF}_{4}$. Figure 13 shows that $\mathrm{HF}$ was observed at peak temperatures of 1,203 and $1,301{ }^{\circ} \mathrm{C}$, whereas $\mathrm{SiF}_{4}$ occurred at peak temperatures of 1,327 and $1,356{ }^{\circ} \mathrm{C}$. Apparently, $\mathrm{F}$ contained in the $\mathrm{Al}_{2} \mathrm{SiO}_{4}(\mathrm{~F}, \mathrm{OH})_{2}$ sample reacted with $\mathrm{H}$ present in $\mathrm{OH}$ groups into $\mathrm{HF}$ during the first and second mass loss step, and then with $\mathrm{Si}$ present in $\mathrm{SiO}_{4}$ into $\mathrm{SiF}_{4}$ during the second and third mass loss step. This example demonstrates 


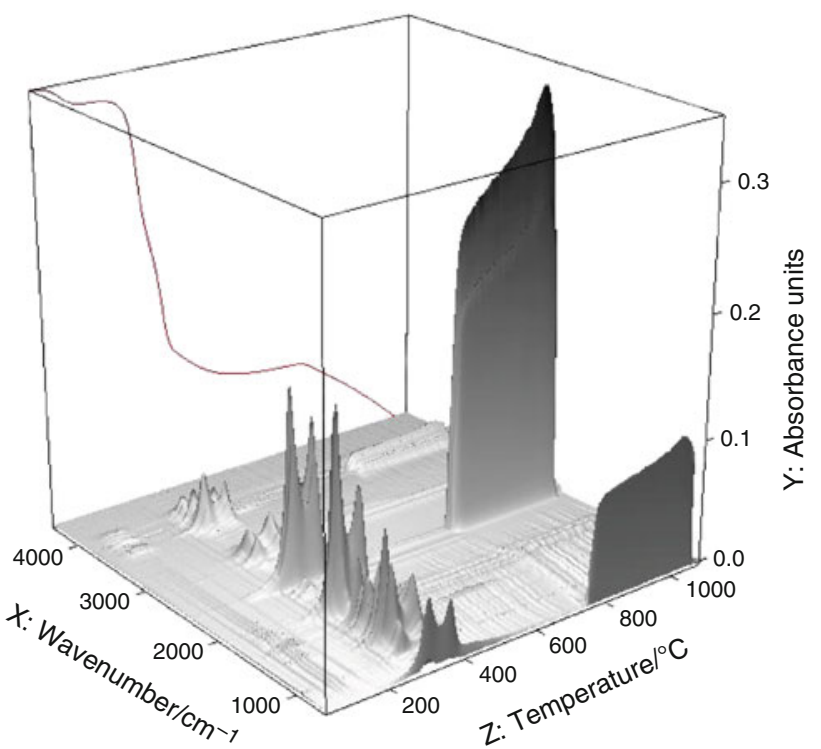

Fig. 7 Wavenumber-dependent FT-IR absorbance of the straw sample as a function of temperature. The corresponding TG curve is shown in the rear $Z Y$ plane again that the detection of evolved gases allows for a detailed interpretation of decomposition steps detected by thermogravimetry.

Direct coupling versus transfer line coupling

Various samples from the fields of ceramics, inorganics, organics (biomass and polymers) were furthermore measured in order to investigate the difference between the direct STA-FT-IR coupling and state-of-the-art STA-FTIR coupling using a heated transfer line (see "Experimental setup" section). All other measurement conditions like heating rate, sample mass, and crucible were chosen as identical as possible - at least for each pair of measurements done with different coupling techniques. We observed for most of the samples very similar results and no significant difference between direct and transfer line coupling. In all cases, a good correlation between the mass loss and the infrared absorbance was found and evolved gases of various kinds could be identified via their FT-IR
Fig. 8 FT-IR spectrum of the straw sample measured at $302{ }^{\circ} \mathrm{C}$ together with the database spectra of $\mathrm{CO}_{2}, \mathrm{CO}$, formic acid $\mathrm{HCOOH}$, and $\mathrm{H}_{2} \mathrm{O}$ (from top to bottom). The spectra were rescaled and shifted for clarity
Fig. 9 Temperature-dependent mass change (TG), rate of mass change (DTG, dashed) and FTIR traces for $\mathrm{H}_{2} \mathrm{O}$ (dashed), $\mathrm{CO}$ (dotted), $\mathrm{CO}_{2}$, formic acid $\mathrm{HCOOH}$, and $\mathrm{CH}_{4}$ (each trace in individual arbitrary units). The gas atmosphere was switched from nitrogen to air at $740{ }^{\circ} \mathrm{C}$
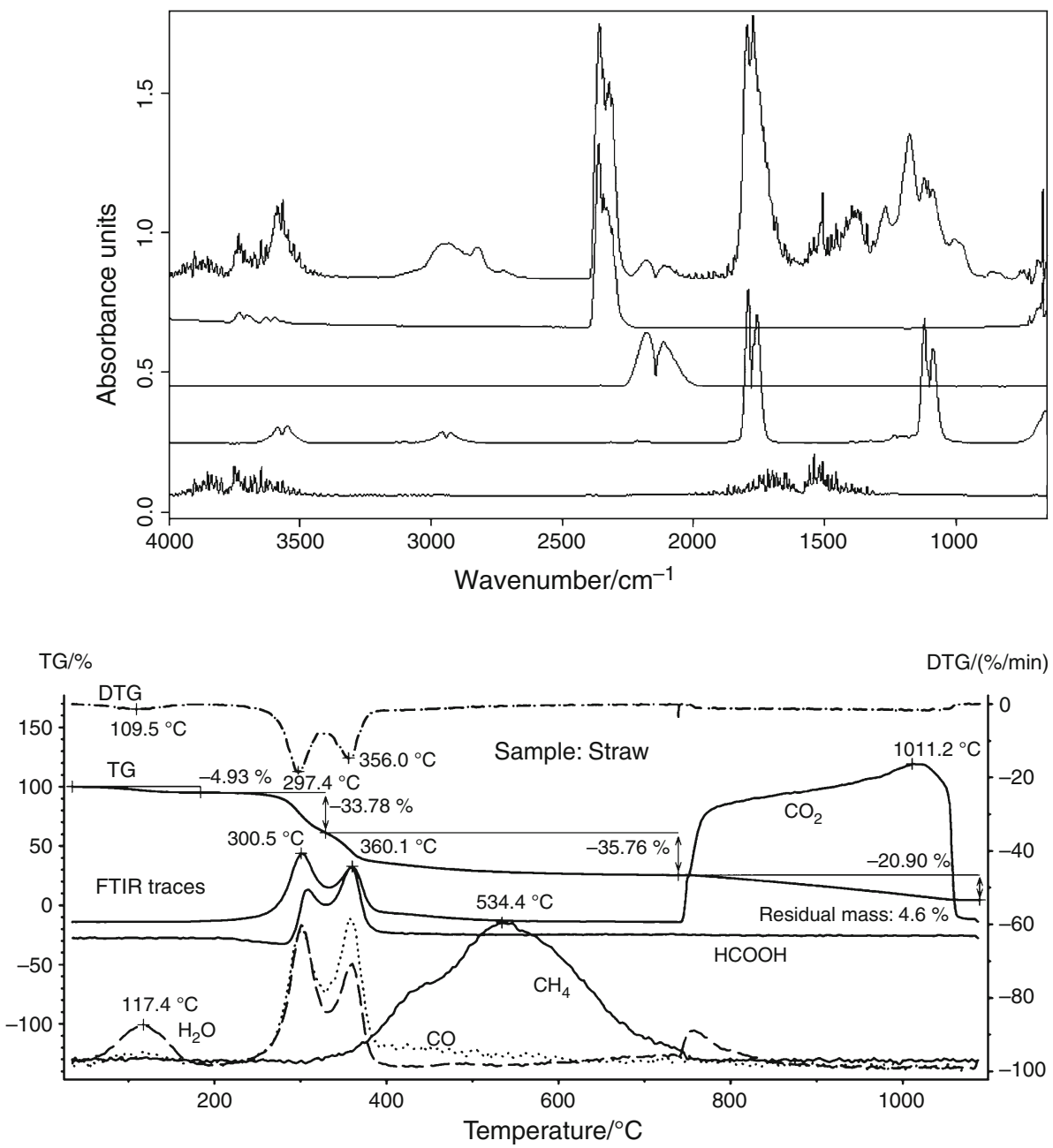
Fig. 10 Temperaturedependent mass change (TG), rate of mass change (DTG, dashed), heat flow rate (DSC), and Gram-Schmidt signal (GS) of a topaz sample

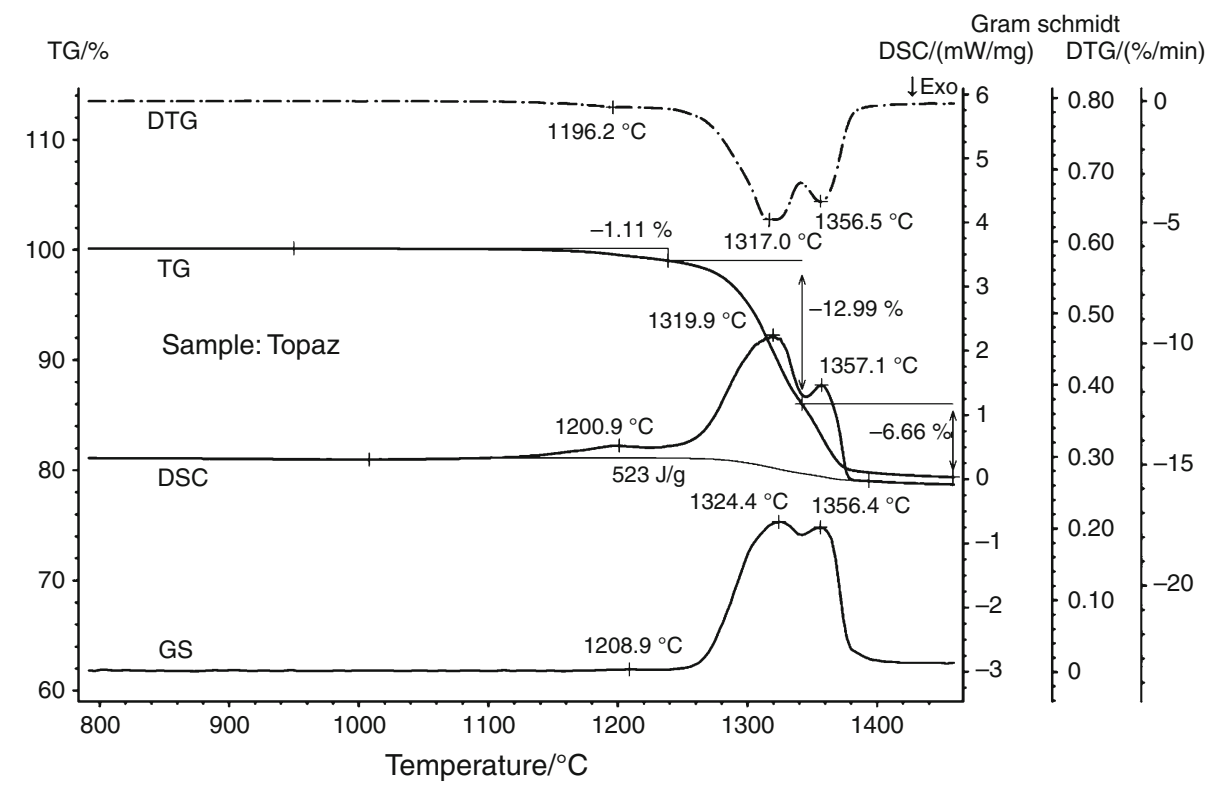

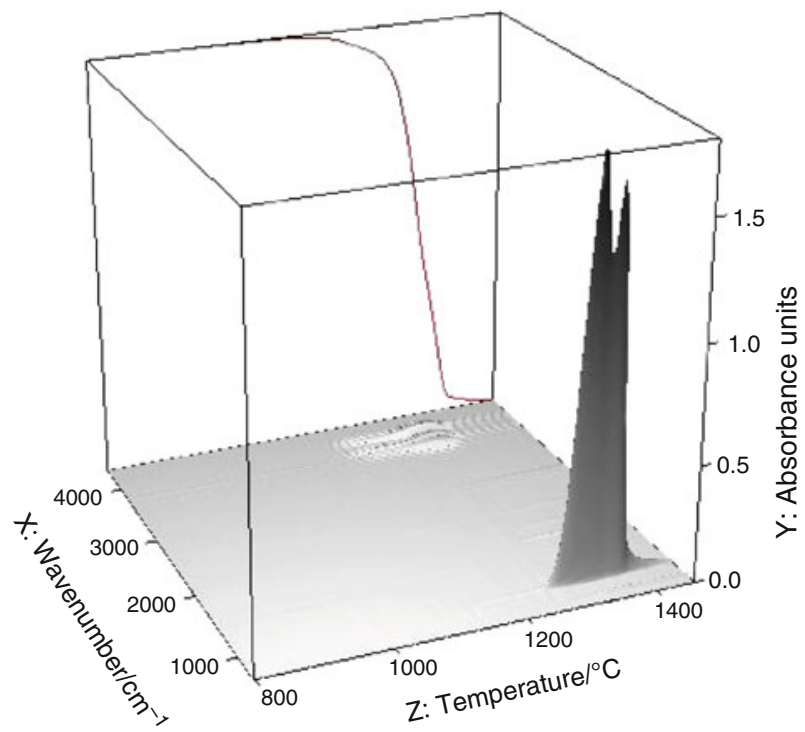

Fig. 11 Wavenumber-dependent FT-IR absorbance of the topaz sample as a function of temperature. The corresponding TG curve is shown in the rear $Z Y$ plane

spectra. Exemplary results obtained for straw powder already discussed above are shown in Fig. 14. The initial sample mass was $(13.8 \pm 0.2) \mathrm{mg}$ and open alumina crucibles, a dynamic nitrogen atmosphere (flow rate: $70 \mathrm{~mL} \mathrm{~min}{ }^{-1}$ ) and a heating rate of $10 \mathrm{~K} \mathrm{~min}^{-1}$ were applied. The first pyrolysis step was observed identically and during the second step, the temperature of the GramSchmidt maximum was slightly closer to the DTG maximum in case of the direct coupling.

A possible influence of the transfer line on the gas transport was studied by evaluating the shift between the Gram-Schmidt maximum and the DTG maximum during a decomposition (or evaporation) step. This shift should reflect the transport of the evolved gases from the sample into the gas cell of the FT-IR spectrometer. Figure 15 summarizes the differences of the temperature shift between the Gram-Schmidt maximum and the DTG maximum measured with transfer line and measured without transfer line (direct coupling between STA and FT-IR) for all measured substances. Most of the data points are slightly above zero which means that the evolved gases reach the FT-IR spectrometer slightly later in case of the transfer line coupling. When disregarding the data points for naphthalene, polyamide 6 (PA6), polyethylene (PE), and polypropylene (PP) discussed below, the mean value is $0.8 \mathrm{~K}$. This temperature shift which is negligible from the practical point of view corresponds to a time shift of $0.8 \mathrm{~K} / 20 \mathrm{~K} \mathrm{~min}^{-1}=0.04 \mathrm{~min}=2.4 \mathrm{~s}$. This time shift is in accordance with the time that can be estimated for the entire gas flow to pass the coupling adaptor and the transfer line in comparison with the direct connection to the gas cell: $3.5 \mathrm{~mL} / 70 \mathrm{~mL} \mathrm{~min}{ }^{-1}=0.05 \mathrm{~min}=3.0 \mathrm{~s}$. The volume of $3.5 \mathrm{~mL}$ is the sum of the inner volume of the transfer line of $3.1 \mathrm{~mL}$ and the inner volume of the coupling adapter of $1.5 \mathrm{~mL}$ minus the inner volume of the connection tube of the direct coupling of $1.1 \mathrm{~mL}$. The flow rate of the nitrogen purge gas is $70 \mathrm{~mL} \mathrm{~min}{ }^{-1}$.

For the samples naphthalene, PA6 and the polyolefin samples PE and PP, larger temperature differences of up to $11 \mathrm{~K}$ (for PA6) were observed as it is again visible from Fig. 15. These shifts are presumably due to interaction of the evolved gases with the transfer line like partial condensation of the gases which may cause a delayed gas transfer.

Depicted in Fig. 16 are the measurement results for the PA6 samples. They had an initial mass of $(9.60 \pm 0.05) \mathrm{mg}$ 
Fig. 12 FT-IR spectrum of the topaz sample measured at $1,333{ }^{\circ} \mathrm{C}(t o p)$ together with the database spectra of $\mathrm{SiF}_{4}$ (middle) and HF (bottom)

Fig. 13 Temperaturedependent mass change (TG), rate of mass change (DTG, dashed), and FT-IR traces for $\mathrm{HF}$ (dashed) and $\mathrm{SiF}_{4}$ of the topaz sample

Fig. 14 Temperaturedependent mass change (TG), rate of mass change (DTG), and Gram-Schmidt signal (GS) of two straw samples measured with the FT-IR spectrometer coupled directly to the STA (full lines) and measured with a heated transfer line between STA and FT-IR (dotted lines)
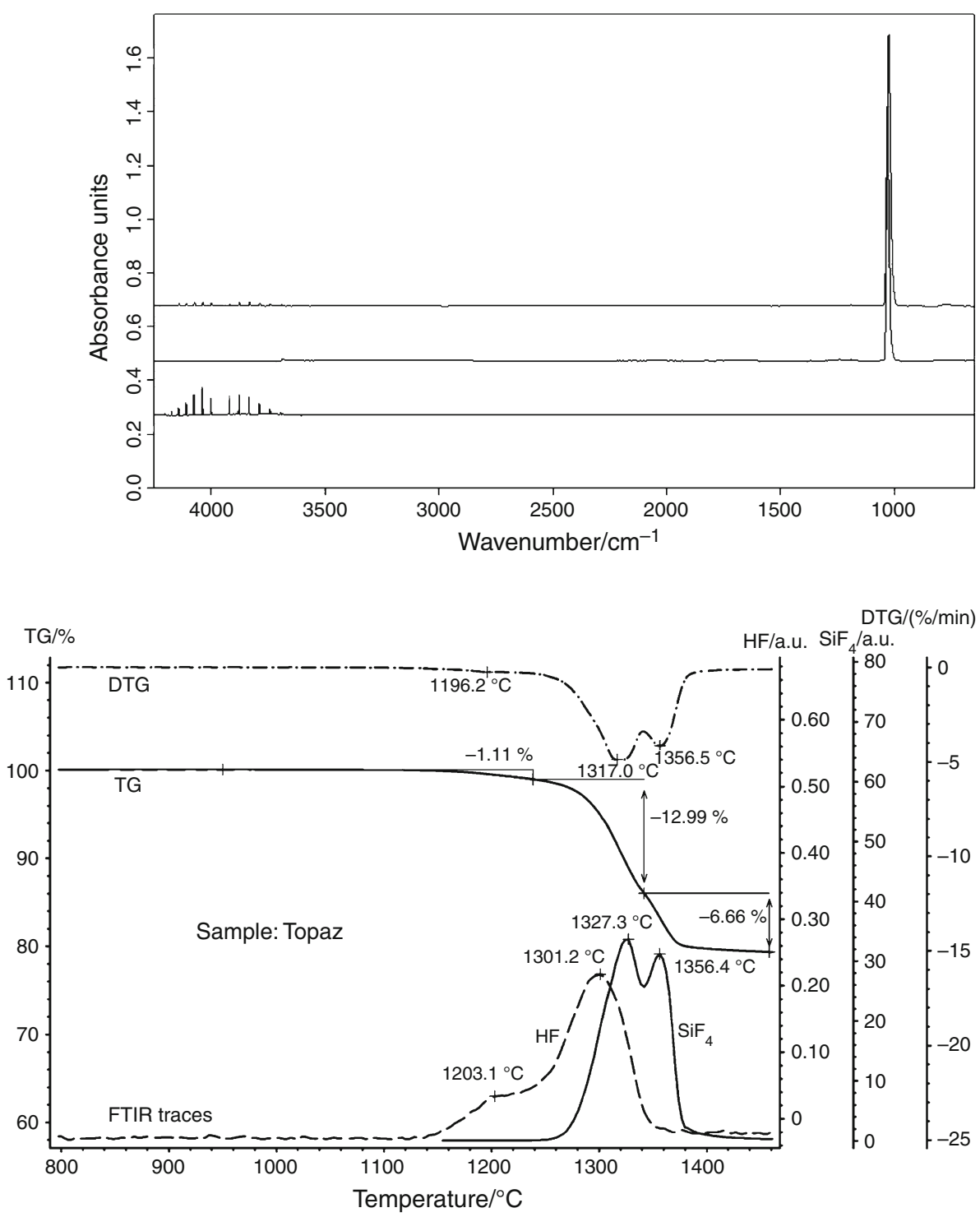

Gram schmidt

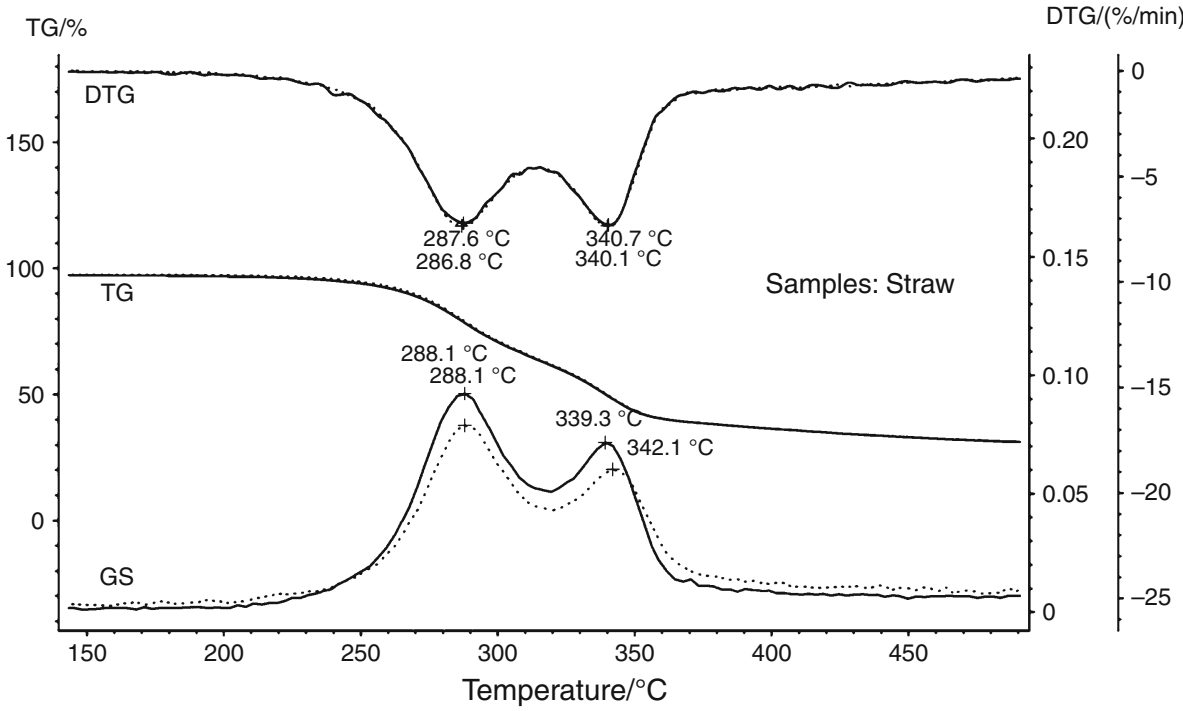


Fig. 15 Difference of the temperature shift between the Gram-Schmidt maximum and the DTG maximum measured with a transfer line and measured without a transfer line (direct coupling between STA and FT-IR) for various substances. The $x$-axis shows the mean DTG peak temperature of each pair of substances. Most of the measurements were carried out at a heating rate of $20 \mathrm{~K} \mathrm{~min}^{-1}$

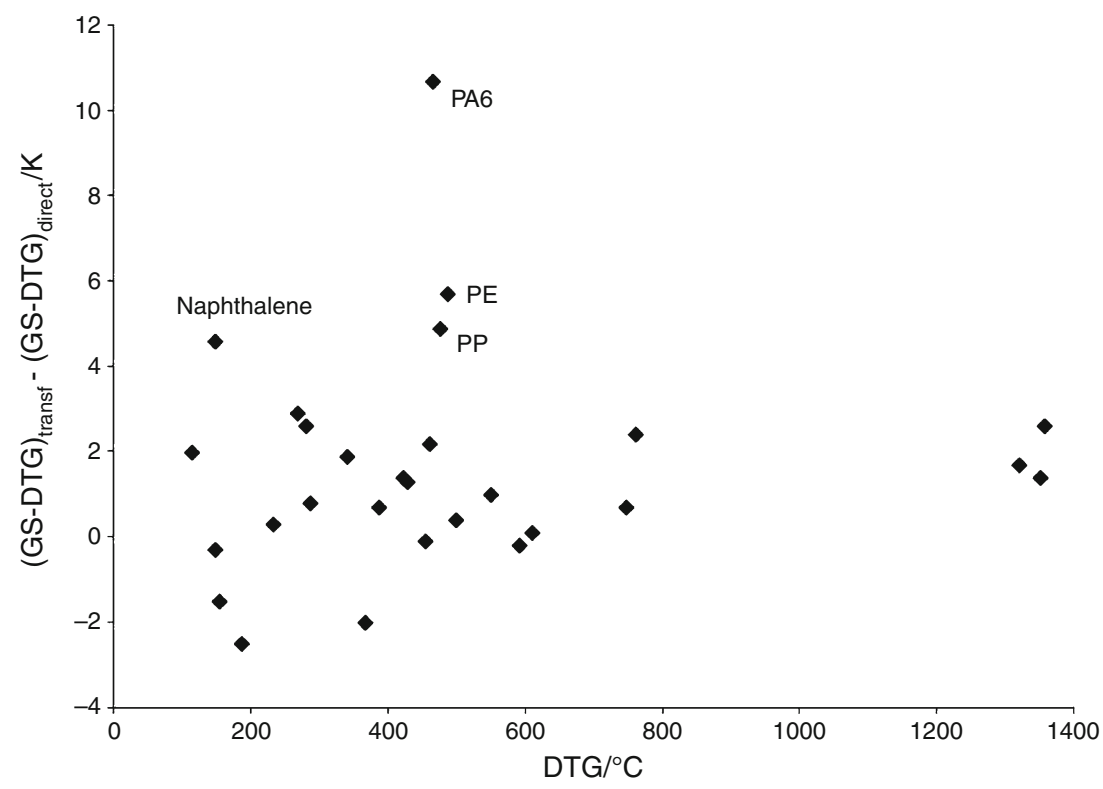

and were measured in open alumina crucibles in dynamic nitrogen atmosphere (flow rate: $70 \mathrm{~mL} \min ^{-1}$ ) and at a heating rate of $20 \mathrm{~K} \mathrm{~min}^{-1}$. Both measurements revealed very similar TG and DTG results. The first mass loss step of about $2 \%$ is due to the release of water which was detected by FT-IR (this can, however, not be seen in the GramSchmidt trace). However, during the main decomposition of PA6 where the expected molecule hexahydro-2-azepinone was detected by FT-IR, the Gram-Schmidt maximum observed for the measurement with direct coupling occurred at $466{ }^{\circ} \mathrm{C}$ and thus only about $2 \mathrm{~K}$ above the DTG peak. In contrast, the shift was about $480-467{ }^{\circ} \mathrm{C}=13 \mathrm{~K}$ in case of the transfer line measurement. This demonstrates a significantly better correlation of the FT-IR absorption with the mass loss in case of the direct coupling, and thus the advantage of the direct coupling in case of condensable gases evolved from samples like PA6.

Quantification of evolved gases

Some aspects of quantification of evolved gases should be discussed on the base of the measurement displayed in Fig. 17. A $\mathrm{CaCO}_{3}$ sample with an initial mass of $m_{0}=3.429 \mathrm{mg}$ was heated up at a rate of $10 \mathrm{~K} \mathrm{~min}^{-1}$ in a dynamic nitrogen atmosphere (flow rate: $70 \mathrm{~mL} \mathrm{~min}{ }^{-1}$ ). Partial decomposition of the sample according to $\mathrm{CaCO}_{3} \rightarrow \mathrm{CaO}+\mathrm{CO}_{2}$ is observed between 600 and $800{ }^{\circ} \mathrm{C}$. The release of $\mathrm{CO}_{2}$ can be seen from the maximum of the (dimensionless) $\mathrm{CO}_{2}$ trace detected in the same temperature range. Again, the integrated FT-IR absorbance in the range of $2,200-2,450 \mathrm{~cm}^{-1}$ was used where $\mathrm{CO}_{2}$ shows the strongest absorbance of infrared radiation. The substance $\mathrm{CaCO}_{3}$ is certainly a sample which does not require an independent quantification of the evolved gas since $\mathrm{CO}_{2}$ is the only gas released during the decomposition. And the amount of $\mathrm{CO}_{2}$ is directly measured by thermogravimetry: $m\left(\mathrm{CO}_{2}\right)=43.94 \% \cdot m_{0}=1.507 \mathrm{mg}$. On the other hand, the measurement of $\mathrm{CaCO}_{3}$ can serve for a calibration of the FT-IR sensitivity for $\mathrm{CO}_{2}$. The timeintegral of the (dimensionless) $\mathrm{CO}_{2}$ trace during the mass loss visible in Fig. 17 should be proportional to the amount of $\mathrm{CO}_{2}$ and the FT-IR sensitivity can thus be calculated to $1,299 \mathrm{~s} / 1.507 \mathrm{mg}=862 \mathrm{~s} \mathrm{mg}^{-1} \mathrm{CO}_{2}$. This information could be used for the quantification of $\mathrm{CO}_{2}$ evolved from unknown samples.

Before and after the decomposition of $\mathrm{CaCO}_{3}$, calibration pulses of $9.9 \% \mathrm{CO}_{2}$ in $90.1 \% \mathrm{~N}_{2}$ with volumes of 0.25 and $1.00 \mathrm{~mL}$ were injected into the STA instrument by means of the Pulse TA ${ }^{\circledR}$ and detected by the FT-IR spectrometer (see again Fig. 17). From the corresponding peaks of the $\mathrm{CO}_{2}$ trace which exhibit a good repeatability and no significant temperature dependence, mean peak areas of 36.6 and $144.7 \mathrm{~s}$ were evaluated for the 0.25 and $1.00 \mathrm{~mL}$ pulses. The calculated mean area for the injection of $1 \mathrm{~mL} \mathrm{CO}_{2}$ is thus $0.5 \cdot(4 \times 36.6 \mathrm{~s}+144.7 \mathrm{~s})=145.6 \mathrm{~s}$. This leads to a sensitivity of (100/9.9) $145.6 \mathrm{~s} \mathrm{~mL}^{-1} \mathrm{CO}_{2}=1,471 \mathrm{~s} \mathrm{~mL}^{-1}$ $\mathrm{CO}_{2}$ which can be transformed to $827 \mathrm{~s} \mathrm{mg}^{-1} \mathrm{CO}_{2}$ using the density of $\mathrm{CO}_{2}$ of $1.778 \mathrm{~g} \mathrm{~mL}^{-1}$ at ambient laboratory conditions $\left(34{ }^{\circ} \mathrm{C}, 1,024 \mathrm{mbar}\right)$. The sensitivity of $827 \mathrm{~s} \mathrm{mg}^{-1} \mathrm{CO}_{2}$ determined by using the Pulse $\mathrm{TA}^{\circledR}$ is within $4 \%$ identical with the value of $862 \mathrm{~s} \mathrm{mg}^{-1} \mathrm{CO}_{2}$ obtained from the decomposition of $\mathrm{CaCO}_{3}$ (see above) which reflects the typical accuracy of the Pulse $\mathrm{TA}^{\circledR}$.

For a correct quantification of evolved gases, the linearity of the detected FT-IR absorbance should be considered [12]. Figure 18 shows that for example in case of $\mathrm{CO}_{2}$, 
Fig. 16 Temperaturedependent mass change (TG), rate of mass change (DTG), and Gram-Schmidt signal (GS) of two PA6 samples measured with the FT-IR spectrometer coupled directly to the STA (full lines) and measured with a heated transfer line between STA and FT-IR (dotted lines)
Fig. 17 Temperaturedependent mass change (TG) of a $\mathrm{CaCO}_{3}$ sample together with the FT-IR trace for $\mathrm{CO}_{2}$. Before and after the decomposition step, several calibration pulses of $9.9 \% \mathrm{CO}_{2}$ in $90.1 \% \mathrm{~N}_{2}$ with volumes of 0.25 and $1.00 \mathrm{~mL}$ were injected using the NETZSCH Pulse TA ${ }^{\circledR}$
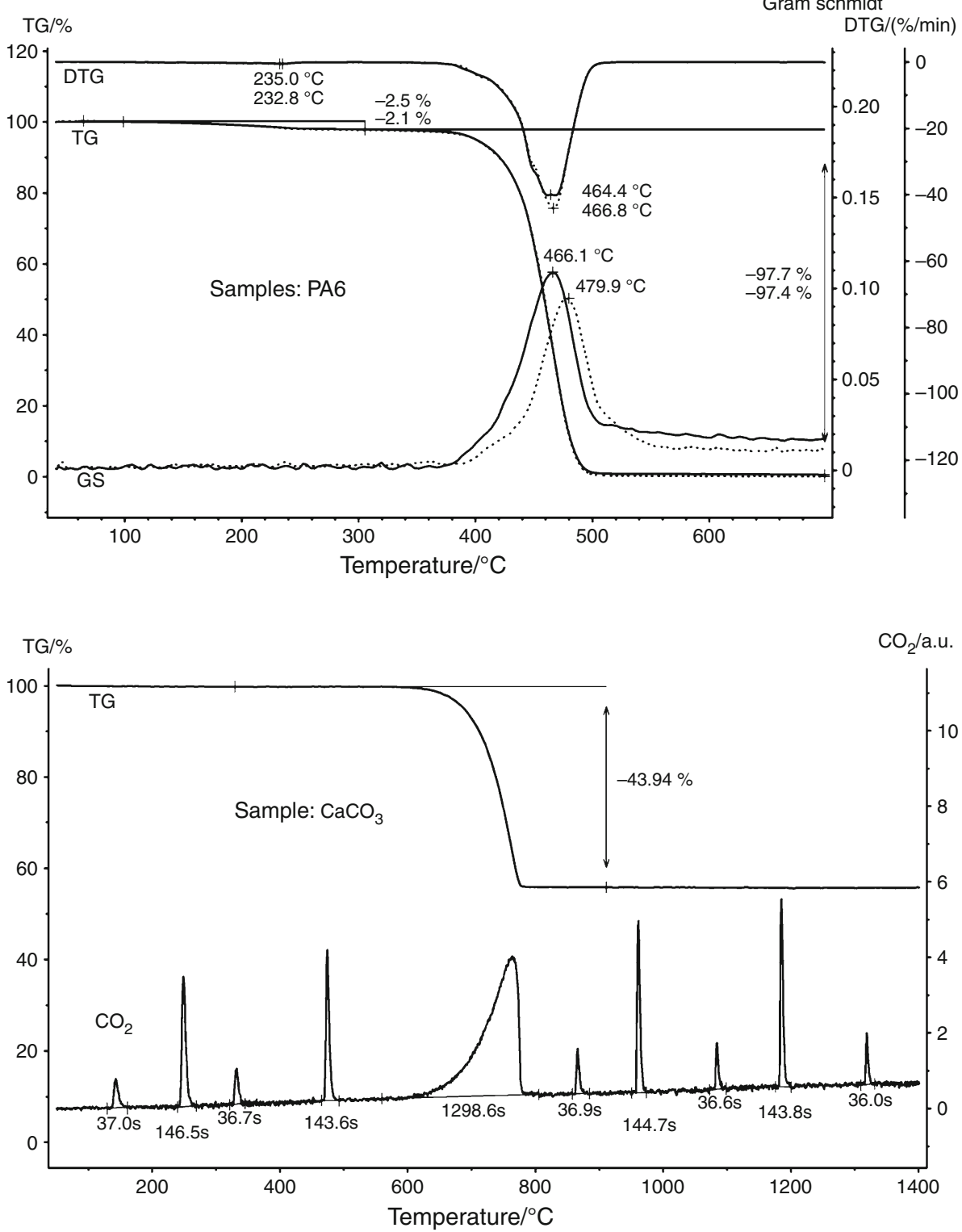

the absorbance at $2,357 \mathrm{~cm}^{-1}$, where maximum absorbance for $\mathrm{CO}_{2}$ occurs, is strongly nonlinear. The origin of nonlinearity is presumably the finite spectral resolution of the FT-IR detection and furthermore deviation from Lambert-Beer's law due to molecule-molecule interactions at higher concentrations [12, 13]. Approximately linear behavior was observed at concentrations below about $1 \%$ (see inset of Fig. 18).

In typical sample measurements, the relevance of nonlinearity depends on the experimental conditions like the sample mass, the heating rate, the flow rate of the purge gas, and furthermore the spectral resolution, acquisition rate and the evaluated wave number region of the FT-IR measurement [12]. Exemplary results are displayed in Fig. 19, where the decomposition of $\mathrm{NaHCO}_{3}$ samples with different initial masses in the range of $1.5-72.44 \mathrm{mg}$ is considered. The heating rate and purge gas flow rate were $10 \mathrm{~K} \mathrm{~min}^{-1}$ and $70 \mathrm{~mL} \mathrm{~min}{ }^{-1} \mathrm{~N}_{2}$ for all measurements. The well-known substance $\mathrm{NaHCO}_{3}$ decomposes in the temperature range between about 100 and $200{ }^{\circ} \mathrm{C}$ releasing $\mathrm{CO}_{2}$ and $\mathrm{H}_{2} \mathrm{O}$ at the same time. FT-IR traces were calculated integrating the FT-IR absorbance in the range of 2,200 and $2,450 \mathrm{~cm}^{-1}$ for $\mathrm{CO}_{2}$ and in the range between 3,400 and $4,000 \mathrm{~cm}^{-1}$ for $\mathrm{H}_{2} \mathrm{O}$. In the linear regime, the integral of the FT-IR traces (peak area) should be proportional to the mass loss or-in other words- the peak area divided by the mass loss should be constant. This was the case for $\mathrm{CO}_{2}$ only below a mass loss of about $3 \mathrm{mg}$ and a significant decrease of the sensitivity occurred at higher mass losses. The same tendency was already shown in Fig. 18. The observed nonlinearity is significantly stronger than reported by Eigenmann et al. [12]. For $\mathrm{H}_{2} \mathrm{O}$, the data 
Fig. 18 FT-IR absorbance at $2,357 \mathrm{~cm}^{-1}$ as a function of the absolute $\mathrm{CO}_{2}$ concentration. Data with filled symbols were created purging the instrument with mixtures of pure $\mathrm{CO}_{2}$ and pure $\mathrm{N}_{2}$ while mixtures of $10 \%$ $\mathrm{CO}_{2}$ in $90 \% \mathrm{~N}_{2}$ and pure $\mathrm{N}_{2}$ were used for the data with open symbols. The entire gas flow rate was always $100 \mathrm{~mL} \mathrm{~min}^{-1}$ and the required individual flows of $\mathrm{CO}_{2}, \mathrm{~N}_{2}$, and $10 \%$ $\mathrm{CO}_{2}$ in $90 \% \mathrm{~N}_{2}$ were controlled using the electronic mass flow controllers (MFCs) of the STA instrument

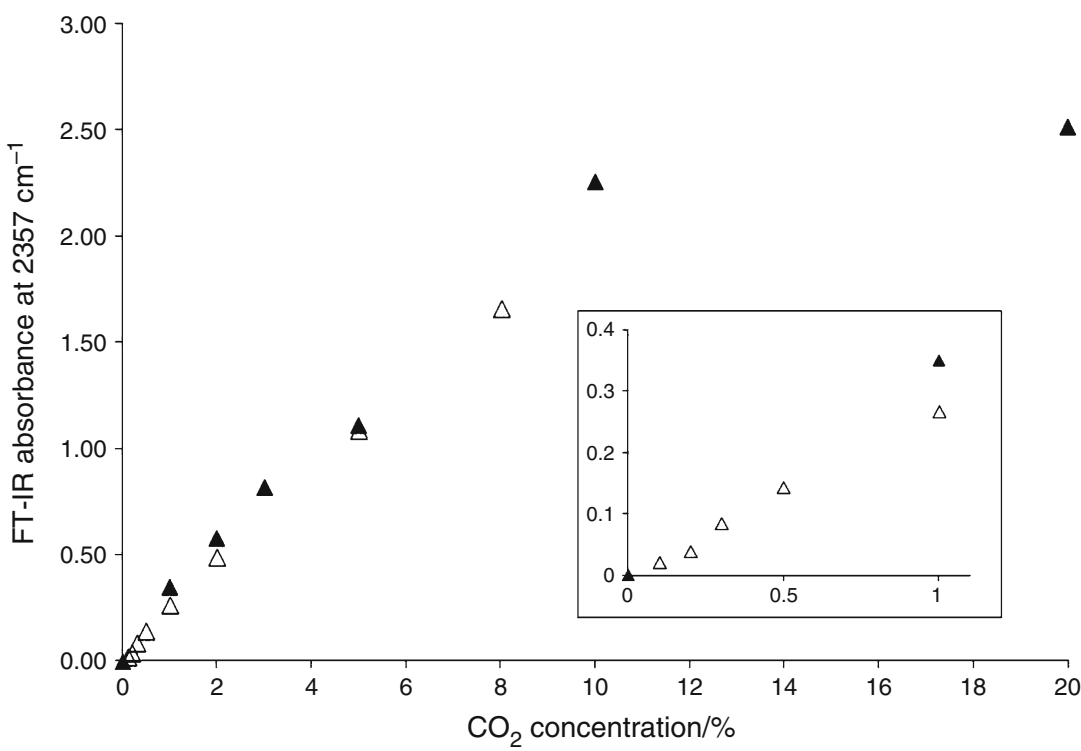

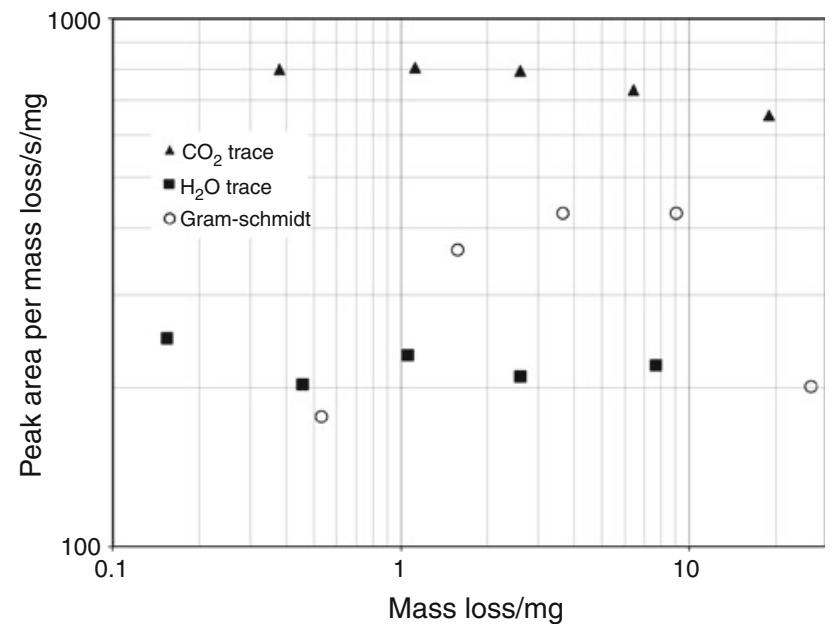

Fig. 19 Peak area per mass loss of $\mathrm{CO}_{2}, \mathrm{H}_{2} \mathrm{O}$, and Gram-Schmidt traces measured during the decomposition of $\mathrm{NaHCO}_{3}$ samples with different initial masses (a heating rate of $10 \mathrm{~K} \mathrm{~min}^{-1}$ and $70 \mathrm{~mL} \mathrm{~min}{ }^{-1} \mathrm{~N}_{2}$ purge gas were used) as a function of the mass loss, respectively. The Gram-Schmidt data were multiplied by 100 for clarity

exhibit a larger scatter (see again Fig. 19) which is due to the stronger influence of the $\mathrm{H}_{2} \mathrm{O}$ background; nonlinearity could not be observed within the scatter of up to $20 \%$. In contrast, the areas of the Gram-Schmidt traces were practically not proportional to the mass loss which means that the Gram-Schmidt trace does not appear to be suitable for quantification of evolved gases-at least not when several gases are evolved at the same time. In summary, a proper quantification of evolved gases is feasible when taking into account possible nonlinearity [12]. The simplest way is certainly to work in the linear regime which should, however, be confirmed by several measurements. Another solution would be to recalibrate the FT-IR absorbance regarding the nonlinearity which could be derived from both kinds of data shown either in Fig. 18 or in 19 [14].

\section{Conclusions}

A novel, direct STA-FT-IR coupling without any transfer line was presented. The use of this compact STA-FT-IR system called Perseus was demonstrated for several samples from the field of organics (naphthalene), biomass (straw) as well as ceramics (topaz). A good correlation between detected mass loss steps and evolved gases was shown as well as the possibility of identification of evolved gases via library search. Measurements with direct Perseus coupling were furthermore compared with measurements on the same samples carried out with state-of-the-art transfer line coupling. On the one hand, very similar results were obtained for most samples and it was shown that the time delay due to the volume of the transfer line is rather negligible. In case of highly condensable gases evolved, e.g., from polyamide the direct Perseus coupling is on the other hand advantageous compared to transfer line coupling. These results followed in particular from an evaluation of the shift between maxima of the derivative of TG and the corresponding maxima of the Gram-Schmidt traces.

Quantification of evolved gases was furthermore addressed. It is feasible either using calibration samples like $\mathrm{CaCO}_{3}$ which evolves a known amount of $\mathrm{CO}_{2}$ or employing the pulse thermal analysis technique. The latter allows for an injection of defined volumes of calibration gases into the thermal analyzer. However, the nonlinearity of detected FT-IR signals at higher gas concentrations has 
to be taken into account for a proper quantitative analysis. Linear and nonlinear regimes were distinguished by exemplary measurements on $\mathrm{NaHCO}_{3}$ with different initial masses.

Open Access This article is distributed under the terms of the Creative Commons Attribution License which permits any use, distribution, and reproduction in any medium, provided the original author(s) and the source are credited.

\section{References}

1. Post E, Rahner S, Möhler A, Rager A. Study of recyclable polymer automobile undercoatings containing PVC using TG/ FTIR. Thermochem Acta. 1995;263:1-6.

2. Zou H, Yi C, Wang L, Liu H, Xu W. Thermal degradation of poly(lactic acid) measured by thermogravimetry coupled to Fourier transform infrared spectroscopy. J Therm Anal Calorim. 2009;97:929-35.

3. Mothé C, de Castro BCS, Mothé M. Characterization by TG/ DTG/DSC and FTIR of frying and fish oil residues to obtain biodiesel. J Therm Anal Calorim. 2011;106:811-7.

4. Huang N, Wang J. A TGA-FTIR study on the effect of $\mathrm{CaCO}_{3}$ on the thermal degradation of EBA copolymer. J Anal Appl Pyrol. 2009;84:124-30.
5. Sanders JP, Gallagher PK. Kinetics of the oxidation of magnetite using simultaneous TG/DSC. J Therm Anal Calorim. 2003;72: 777-89.

6. Daßler A, Feltz A, Jung J, Ludwig W, Kaisersberger E. Characterization of rutile and anatase powders by thermal analysis. J Therm Anal Calorim. 1988;33:803-9.

7. Wiss J, Schmuck J-L. Cleaning validation using thermogravimetry. J Therm Anal Calorim. 2011;104:315-21.

8. Maciejewski M, Baiker A. Pulse thermal analysis. In: Brown ME, Gallagher PK, editors. Handbook of thermal analysis and calorimetry, vol. 5. Amsterdam: Elsevier; 2008. p. 93-132.

9. BRUKER Optik GmbH, Rudolf-Plank-Straße 27, 76275 Ettlingen, Germany.

10. Jacob J. The significance of polycyclic aromatic hydrocarbons as environmental carcinogens. Pure Appl Chem. 1996;68:301-8.

11. Maguire V, Svrcek WY, Mehrotra AK. A study of interactions between soil fractions and PAH compounds in thermal desorption of contaminated soils. Can J Chem Eng. 1995;73:844-53.

12. Eigenmann F, Maciejewski M, Baiker A. Influence of the measuring conditions on the quantification of spectroscopic signals in TA-FTIR-MS systems. J Therm Anal Calorim. 2006;83:321-30.

13. Hanst PL, Hanst ST. Gas analysis manual for analytical chemists, vol I: infrared measurements of gases and vapors. Anaheim: Infrared Analysis, Inc.; 1990. p. 31-2.

14. Hanss J. Presented at GEFTA-Fortbildungskurs; 2011. 